\title{
Human placental mesenchymal stem cells ameliorate chemotherapy-induced damage in the testis by reducing apoptosis/ oxidative stress and promoting autophagy
}

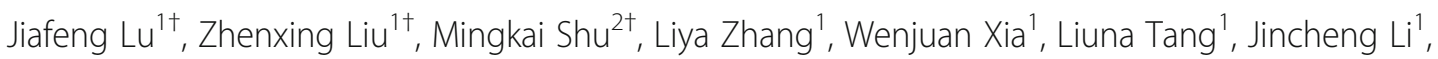
Boxian Huang ${ }^{*^{*}}$ (D) and Hong $\mathrm{Li}^{1^{*}}$

\begin{abstract}
Background: The side effects of busulfan on male reproduction are serious, so fertility preservation in children undergoing busulfan treatment is a major worldwide concern. Human placental mesenchymal stem cells (hPMSCs) have advantages such as stable proliferation and lower immunogenicity that make them an ideal material for stimulating tissue repair, especially restoring spermatogenesis. The protective effects of hPMSCs in busulfan-induced Sertoli cells and in busulfan-treated mouse testes have not been determined. Our study aimed to elaborate the protective effect and potential mechanisms of hPMSCs in busulfan-treated testes and Sertoli cells.

Methods: First, we developed a mouse model of busulfan-induced testicular toxicity in vivo and a mouse Sertoli cell line treated with busulfan in vitro to assess the protective effect and mechanisms of hPMSC treatment on spermatogenesis. Then, the length, width, and weight of the testes were monitored using Vernier calipers.

Furthermore, at 1 week and 4 weeks after the transplantation of hPMSCs, histological sections of testes were stained with hematoxylin-eosin, and the seminiferous tubules with fluid-filled cavities were counted. Through ELISA analysis, testosterone levels and MDA, SOD, LDH, and CAT activities, which are associated with ROS, were detected. Markers of ROS, proliferation (Ki67), and apoptosis (Annexin V) were evaluated by FACS. Next, the fluorescence intensity of proliferation markers (BrdU and SCP3), an antioxidant marker (SIRT1), a spermatogenesis marker (PLZF), and autophagy-related genes (P62 and LC3AB) were detected by fluorescence microscopy. The mRNA expression of $\gamma^{-}$ H2AX, BRCA1, PARP1, PCNA, Ki67, P62, and LC3 was determined by qRT-PCR.

(Continued on next page)
\end{abstract}

\footnotetext{
*Correspondence: huangboxiannj@163.com; hongliszivf@163.com

${ }^{\dagger}$ Jiafeng Lu, Zhenxing Liu and Mingkai Shu contributed equally to this work.

'Center of Reproduction and Genetics, The affiliated Suzhou Hospital of Nanjing Medical University, Suzhou Municipal Hospital, Gusu School, State Key Laboratory of Reproductive Medicine, Nanjing Medical University, Suzhou 215002, China

Full list of author information is available at the end of the article
}

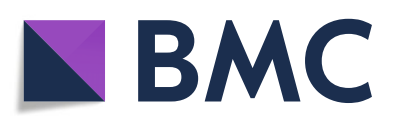

(- The Author(s). 2021 Open Access This article is licensed under a Creative Commons Attribution 4.0 International License, which permits use, sharing, adaptation, distribution and reproduction in any medium or format, as long as you give appropriate credit to the original author(s) and the source, provide a link to the Creative Commons licence, and indicate if changes were made. The images or other third party material in this article are included in the article's Creative Commons licence, unless indicated otherwise in a credit line to the material. If material is not included in the article's Creative Commons licence and your intended use is not permitted by statutory regulation or exceeds the permitted use, you will need to obtain permission directly from the copyright holder. To view a copy of this licence, visit http://creativecommons.org/licenses/by/4.0/. The Creative Commons Public Domain Dedication waiver (http://creativecommons.org/publicdomain/zero/1.0/) applies to the data made available in this article, unless otherwise stated in a credit line to the data. 
(Continued from previous page)

Results: hPMSCs restored disrupted spermatogenesis, promoted improved semen parameters, and increased testosterone levels, testis size, and autophagy in the testis toxicity mouse model induced by busulfan. hPMSCs suppressed the apoptosis of Sertoli cells and enhanced their rate of proliferation in vitro. Additionally, hPMSCs protected against oxidative stress and decreased oxidative damage in the testis toxicity mouse model induced by busulfan. Furthermore, hPMSCs increased the expression of proliferation genes (PCNA and KI67) and decreased the mRNA levels of apoptotic genes such as $\mathrm{Y}-\mathrm{H} 2 \mathrm{AX}, \mathrm{BRCA} 1$, and PARP1.

Conclusions: This research showed that hPMSC injection ameliorated busulfan-induced damage in the testis by reducing apoptosis/oxidative stress and promoting autophagy. The present study offers an idea for a new method for clinical treatment of chemotherapy-induced spermatogenesis.

Keywords: Busulfan, Spermatogenesis, Human placental mesenchymal stem cells, Autophagy, Reactive oxygen species, Apoptosis

\section{Background}

Spermatogenesis of mammals is a profoundly organized and dynamic cell differentiation process with three stages: mitosis, meiosis, and spermatogenesis [1]. In the process of spermatogenesis, Sertoli cells play crucial roles that include regulating multidirectional differentiation and spontaneous recovery of spermatogonia stem cells (SSCs), providing nourishment as well as fundamental support for developing germ cells and so on [2]. Deviation in these processes could lead to abnormal characteristics in the morphology, function, and motility of the sperm [3]. For instance, the spermatogenesis process is susceptible to toxicity, contamination, anticancer medicine, and other factors [4-6]. In particular, spermatogonial progenitor cells (SPCs) are sensitive to the toxicity of busulfan, but the molecular mechanism remains largely unknown [7].

Busulfan is a common chemotherapeutic drug that prevents cellular division, and consequently, germ cells, which have high rates of division, are vulnerable to busulfan [8]. Several studies have focused on the mechanism of busulfan toxicity, such as ROS-induced apoptosis [9]. Nevertheless, the potential mechanism induced by busulfan is very intricate since it probably involves multiple biological reactions, e.g., reactive oxygen species, proliferation, apoptosis, and autophagy [10]. Thus, the side effects of busulfan on male reproduction are so severe that fertility preservation in children undergoing busulfan treatment is a major worldwide concern.

Mesenchymal stem cells (MSCs) hold great promise for rehabilitating the microenvironment of spermatogenesis. For instance, mesenchymal stem cells derived from the human placenta are in clinical trials for a variety of restorative applications [11]. Compared with MSCs from other sources, human placental mesenchymal stem cells (hPMSCs) have the advantages of stable proliferation and low immunogenicity. These characteristics of hPMSCs make them an ideal material for stimulating tissue repair. Our group confirmed that hPMSCs ameliorate premature ovarian insufficiency via NRF2/ HO-1 activation [12]. However, the mechanism by which hPMSCs restore spermatogenesis in busulfan-induced mouse testes is not clear.

Autophagy is a highly conserved membrane-trafficking process for degrading long-lived proteins and organelles by lysosomes. Autophagy starts with the development of a vesicle with a double membrane, which is named an autophagosome. The autophagosome moves along cytoskeletal structures and merges with lysosomes, creating an autolysosome [13]. To date, more than forty autophagy-related (ATG) proteins have been identified $[14,15]$. Upon induction of autophagy in mammals, LC3 is activated by ATG3 and ATG7 and attaches to the lipid-containing membrane. The lipid-containing membrane serves as a scaffold to establish phagophores that become enclosed autophagosomes. Autophagy participates in many non-pathological processes, such as preimplantation development [16], ectoplasmic specialization assembly in Sertoli cells [17], and spermatid differentiation [18]. In addition, oxidative stress above normal physiological levels can damage sperm DNA, leading to male infertility [19]. A previous study also showed that apoptosis is a key physiological process in the development of testes [20]. However, the function of autophagy, apoptosis, and oxidative stress in busulfaninduced spermatogenesis remains largely unknown.

To date, the protective effects of hPMSCs in mouse testes treated with busulfan and in mouse Sertoli cells induced by busulfan have not been elaborated. Therefore, our research aimed to identify whether hPMSCs could ameliorate chemotherapy-induced damage in the testes of mice by reducing apoptosis/oxidative stress and promoting autophagy.

\section{Methods}

Preparation of hPMSCs

After being dissected and immediately placed in solution, samples of the human placenta were thoroughly rinsed in PBS containing antibiotic-antimycotic $(100 \mathrm{U} / \mathrm{ml}$ penicillin 
G and $100 \mathrm{mg} / \mathrm{ml}$ streptomycin; Thermo Fisher Scientific) for $60 \mathrm{~min}$ on ice. The samples were split into quadrants, and then, the villous chorion and chorionic plate were diced to small pieces no more than $1 \mathrm{~mm}$ in length after the removal of the amniotic membrane layer. To release the cells, the minced tissues were enzymatically digested by trypsin $(10 \mathrm{~g})$ in culture medium for $60 \mathrm{~min}$ at $37^{\circ} \mathrm{C}$, and dispase $(4 \mathrm{mg} / \mathrm{ml}$, Thermo Fisher Scientific) plus Collagenase Type IV $(3 \mathrm{mg} / \mathrm{ml}$, Thermo Fisher Scientific) was added. The samples were centrifuged for 5 min at room temperature in culture medium containing $10 \%$ fetal bovine serum (FBS) before the reaction was ended. Approximately $3 \times 10^{7}$ cells were transplanted into each $10-\mathrm{cm}$ cell culture dish. The cells started growing adherently after 3 days, and within 1 week, cell clusters formed. All experiments were performed using 3rd-4th-generation hPMSCs.

\section{RNA extraction and reverse transcription-polymerase chain reaction (RT-PCR)}

After hPMSC treatment, a Qiagen RNeasy Mini Kit (Qiagen, USA) was used to extract total RNA from the testes of the four groups of mice. A Prime-Script RT Reagent Kit (Takara, Japan) was used to reverse transcribe RNA into cDNA, SYBR Premix Ex Taq (Takara, Japan) was used to perform quantitative real-time polymerase chain reaction (PCR) utilizing a Thermal Cycler Dice Real-Time System (Takara, Japan), and the $2^{-\Delta \Delta C t}$ calculation method was employed to analyze the data. The primer sequences for the genes $\gamma-\mathrm{H} 2 \mathrm{AX}, \mathrm{BRCA} \mathrm{I}$, PARP1, PCNA, KI67, P62, and LC3 are shown in Supplementary Table.

\section{Sertoli cell preparation and treatment}

The TM4 mouse Sertoli cell line (Procell, China) was acquired and cultured at $1 \times 10^{5}$ cells per well utilizing specific complete medium for TM4 (Procell, China) in an incubator. The cell medium was changed every 2 days, and the cells were trypsinized and passaged at 80 $90 \%$ confluence. Busulfan was added to Sertoli cells based on a previously described approach with slight alterations [21]. Briefly, Sertoli cells were treated with $10^{-4} \mu \mathrm{M}$ busulfan and cultured in an incubator for $48 \mathrm{~h}$. After that, hPMSCs were cocultured with the busulfaninduced Sertoli cells for $48 \mathrm{~h}$ using a Transwell system. The Sertoli cells were then divided into three groups: the control group (untreated), BU group (busulfantreated), and BU/hPMSC group (treated with hPMSCs after busulfan treatment).

\section{Experimental mouse model}

Nanjing Medical University provided male C57BL/6 mice. They were fed as described in our previous study [22]. A mouse model of testicular toxicity induced by busulfan was established using the previously described approach with some alterations. Briefly, busulfan was dissolved in DMSO and diluted with distilled water to 5 $\mathrm{mg} / \mathrm{mL}$. Busulfan $(40 \mathrm{mg} / \mathrm{kg})$ was injected into the enterocoelia of mice. Approximately $5 \times 10^{6} \mathrm{hPMSCs}$ suspended in normal saline were injected into the testes of mice, which were subsequently sacrificed at 1 or 4 weeks after the hPMSC treatment. Consequently, the mice were divided into three groups: the control group (untreated), BU group (busulfan treated), and BU/hPMSC group (treated with hPMSCs after busulfan treatment).

\section{Testes measurement and histological analysis}

The blood and testes were acquired for ELISA detection and HE staining, respectively. Euthanasia was used on all mice, and the blood, testes, and epididymis were collected for follow-up experiments. Furthermore, the length, width, and weight of the testes were measured using Vernier calipers. After the transplantation of hPMSCs, the testes of mice were fixed with paraformaldehyde. The tissues were dehydrated and then clarified by xylene and paraffin-embedded, and the paraffinembedded blocks were cut into slices of $5-\mu \mathrm{m}$ thickness. As described in a previous study, slices of $5-\mu \mathrm{m}$ thickness were stained with hematoxylin-eosin and examined with an optical microscope [23]. Five typical sections containing convoluted tubules with vacuoles were examined from each testis.

\section{ELISA analysis}

Serum levels of testosterone, superoxide dismutase (SOD), malondialdehyde (MDA), catalase (CAT), and lactate dehydrogenase (LDH) were measured by ELISA (Cayman Chemical, USA). In short, 50- $\mu$ l culture medium or serum was added to the plate and incubated at $37^{\circ} \mathrm{C}$ for $30 \mathrm{~min}$. Then, the wells were washed 5 times for $10 \mathrm{~s}$ each, and the cells were incubated with $50 \mathrm{~mol} / \mathrm{l}$ HRP-coupling reagent at $37^{\circ} \mathrm{C}$ for $60 \mathrm{~min}$. The wells were washed five times for $10 \mathrm{~s}$ each and incubated with a mixture of substrate $\mathrm{B}$ and A solution $(50 \mathrm{~mol} / \mathrm{L})$ at $37^{\circ} \mathrm{C}$ for $30 \mathrm{~min}$; last, the reaction was ended by adding $50 \mu \mathrm{l}$ stop solution. Finally, the absorbance was measured with a spectrophotometer (BioTek, USA).

\section{Fluorescence-activated cell sorting (FACS) analysis}

To detect ROS, Ki67, and Annexin V, Sertoli cells were collected. The mouse testes were digested with $0.25 \%$ trypsin-EDTA to produce a single-cell suspension. Furthermore, the Fixation and Permeabilization Solution Kit (BD, USA) was used to fix and permeabilize the digested cells. The cells were labeled with FITC-conjugated antiAnnexin V (BD, USA), PE-conjugated anti-Ki67 (BD, USA), and PE-conjugated anti-ROS (Abcam, USA) antibodies and their isotype controls at $4{ }^{\circ} \mathrm{C}$ for $30 \mathrm{~min}$. 
After that, flow cytometry (Beckman, USA) was used for analysis according to the manufacturer's instructions.

\section{BrdU assay and immunofluorescence of SCP3, SIRT1, PPLZF, P62, and LC3AB}

First, the slides were dewaxed with xylene, rehydrated with isopropyl alcohol, incubated with a proteinase $\mathrm{K}$ solution, fixed with formaldehyde, and eventually incubated in a DNA labeling solution and an antibody solution. Anti-scp3 antibody, anti-SIRT1 antibody, antiPLZF antibody, anti-P62 antibody, and anti-LC3AB antibody (Abcam, USA) were used for backstaining, and $4 \%$ PFA was used for fixing (Sigma, USA); after that, 0.1\% Triton X-100 (Sigma, USA) was used for permeating, and $4 \%$ bovine serum albumin (BSA, Sigma, USA) was used for blocking. The slides were incubated with the above five antibodies, and BrdU staining was performed overnight at $4{ }^{\circ} \mathrm{C}$. The sections were stained with FITCconjugated secondary antibodies (Jackson ImmunoResearch, West Grove), stained with Hoechst 33342 (Beyotime Biotechnology, China), and evaluated with a fluorescence microscope (Olympus, Japan).

\section{Statistical analysis}

All the experiments in this study were repeated at least three times. Data are expressed as the mean \pm standard deviation. SPSS 22.0 software was used for one-way ANOVA to analyze significant differences, which were defined as a $P$ value less than 0.05 .

\section{Results}

hPMSCs restored disrupted spermatogenesis and raised the levels of testosterone in a mouse model of busulfaninduced testicular toxicity

To investigate the therapeutic potential of hPMSCs to restore busulfan-disrupted spermatogenesis, testosterone levels and phenotypic characteristics of the vas deferens in the three groups were determined by ELISA and HE staining, respectively (Fig. 1). The histopathological pictures show that busulfan markedly damaged spermatogenic cells, while complete spermatogenesis occurred in the control group. After the busulfan treatment, obvious vacuolation (marked by a yellow quincunx) was observed in the basal compartment in paraffin sections (Fig. 1a). The results suggested that the testis toxicity mouse model induced by busulfan was successfully established. One week after hPMSC injection, cell vacuolation in the basement membrane was slightly reduced. Surprisingly, cell vacuolation disappeared entirely in the hPMSCtreated group at 4 weeks. Compared with that in the BU group, the testosterone level in the HPMSC group was slightly increased at 1 week (Fig. 1b). Nevertheless, the testosterone level of the hPMSC-treated group was greatly increased at 4 weeks compared with that of the BU group (Fig. 1c).

\section{hPMSCs promoted improved semen parameters and} increased weight and size of testes in a mouse model of busulfan-induced testicular toxicity

The sperm count of the BU group presented a more than threefold decline compared to that of the control

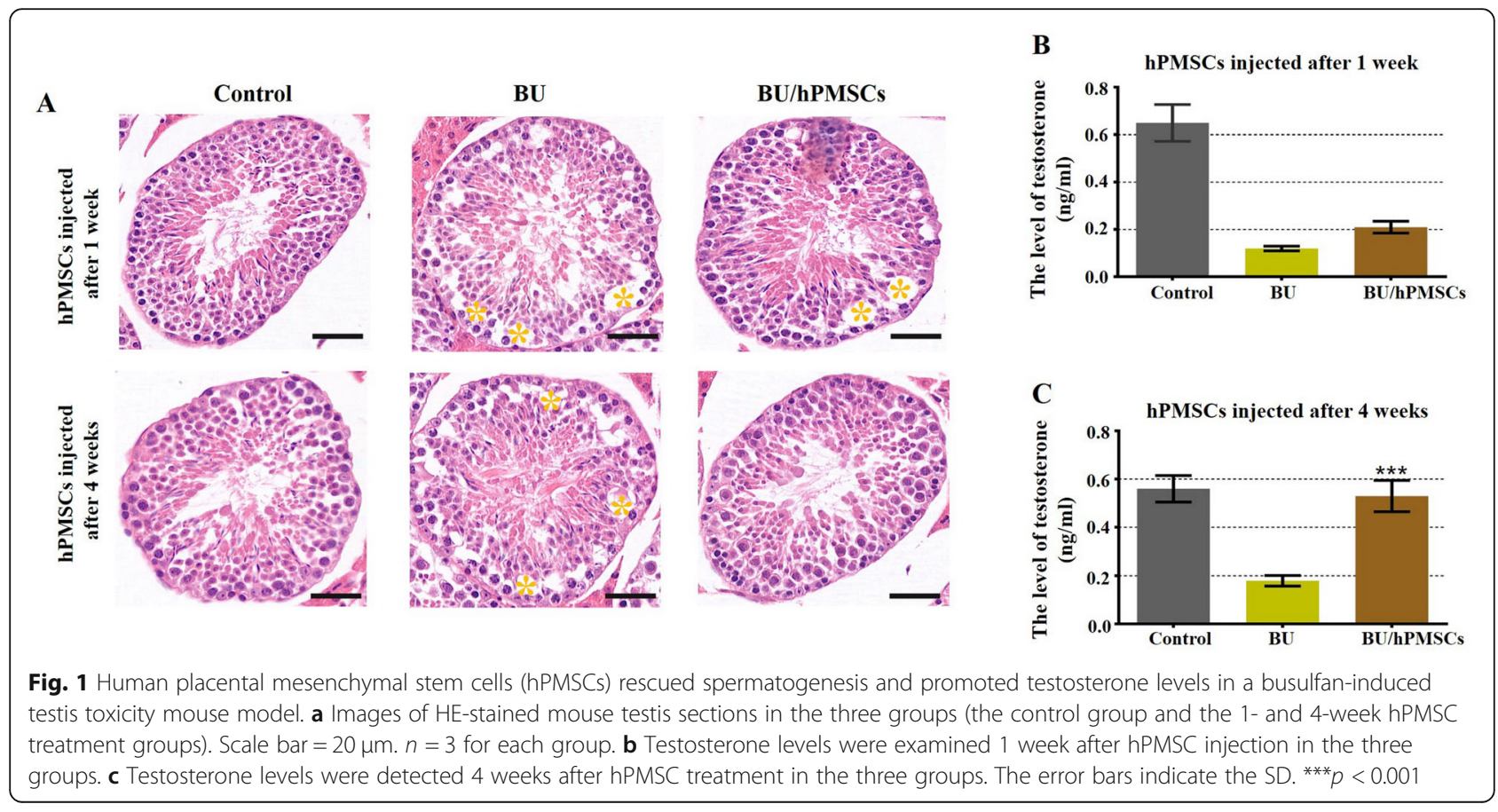


group. The sperm count returned to a level similar to that of the control group at 4 weeks after hPMSC therapy (Fig. 2a). Next, the ratio of sperm cells with normal morphology to those with abnormal morphology decreased greatly in the BU group but rapidly recovered in the BU/hPMSC group compared with that in the control group (Fig. 2a). Additionally, we observed a nearly threefold decrease in the proportion of motile cells in the $\mathrm{BU}$ group, and this proportion was restored at 4 weeks after hPMSC treatment (Fig. 2a). Similarly, the proportion of viable cells declined dramatically in the BU group but returned to the level of the control group at 4 weeks after hPMSC therapy (Fig. 2a). Finally, to determine whether hPMSCs restore testicular function, we measured and compared the weight, length, and width of the mouse left and right testes among the three groups. In the BU group, the width, length, and weight of both the right and left testes were reduced by half. Moreover, the three parameters above markedly increased to normal levels at 4 weeks after hPMSC treatment (Fig. 2b-g).

\section{hPMSCs suppressed the apoptosis of Sertoli cells and enhanced the rate of proliferation}

To investigate the role of hPMSCs in enhancing the proliferation and inhibiting the apoptosis of busulfan- induced Sertoli cells, FACS analysis was employed to quantitatively assess cell viability by the proliferation marker of Ki67 and the apoptosis marker of ANNEXIN $\mathrm{V}$. As shown in Fig. 3a, in the BU/hPMSC group, the rate of apoptosis significantly decreased by $23.8 \%$, which was similar to that of the control group but lower than that of the $\mathrm{BU}$ group. Additionally, the proliferation rate of the BU/hPMSC group increased by $80.9 \%$, which was higher than that of the BU group (Fig. 3b). Moreover, we used qRT-PCR to detect the expression levels of apoptotic genes ( $\gamma$-H2AX, BRCA1, and PARP1) and proliferative genes (PCNA and Ki67). As shown in Fig. 3c, after hPMSC treatment, the expression levels of $\gamma$ H2AX, BRCA1, and PARP1 in the BU/hPMSC group were similar to those in the control group. The expression patterns of PCNA and Ki67 in the BU/hPMSC group were similar to those in the control group but were greatly decreased in the BU group (Fig. 3d). Briefly, hPMSCs suppressed the apoptosis of Sertoli cells and enhanced the rate of proliferation.

\section{hPMSCs enhanced cell proliferation and alleviated apoptosis in vitro}

To explore whether hPMSCs boosted cell proliferation and alleviated apoptosis in vitro, a mouse model of

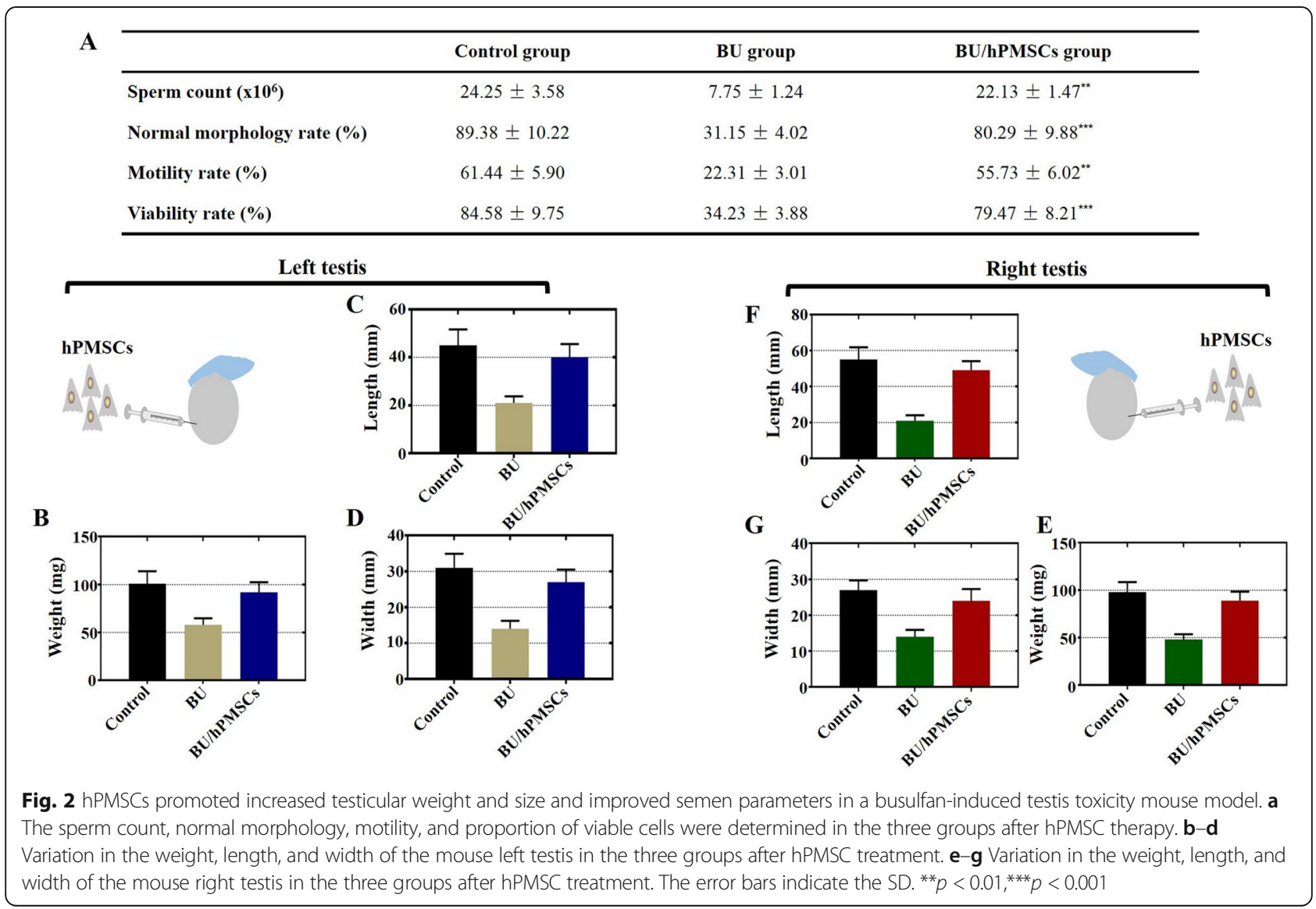




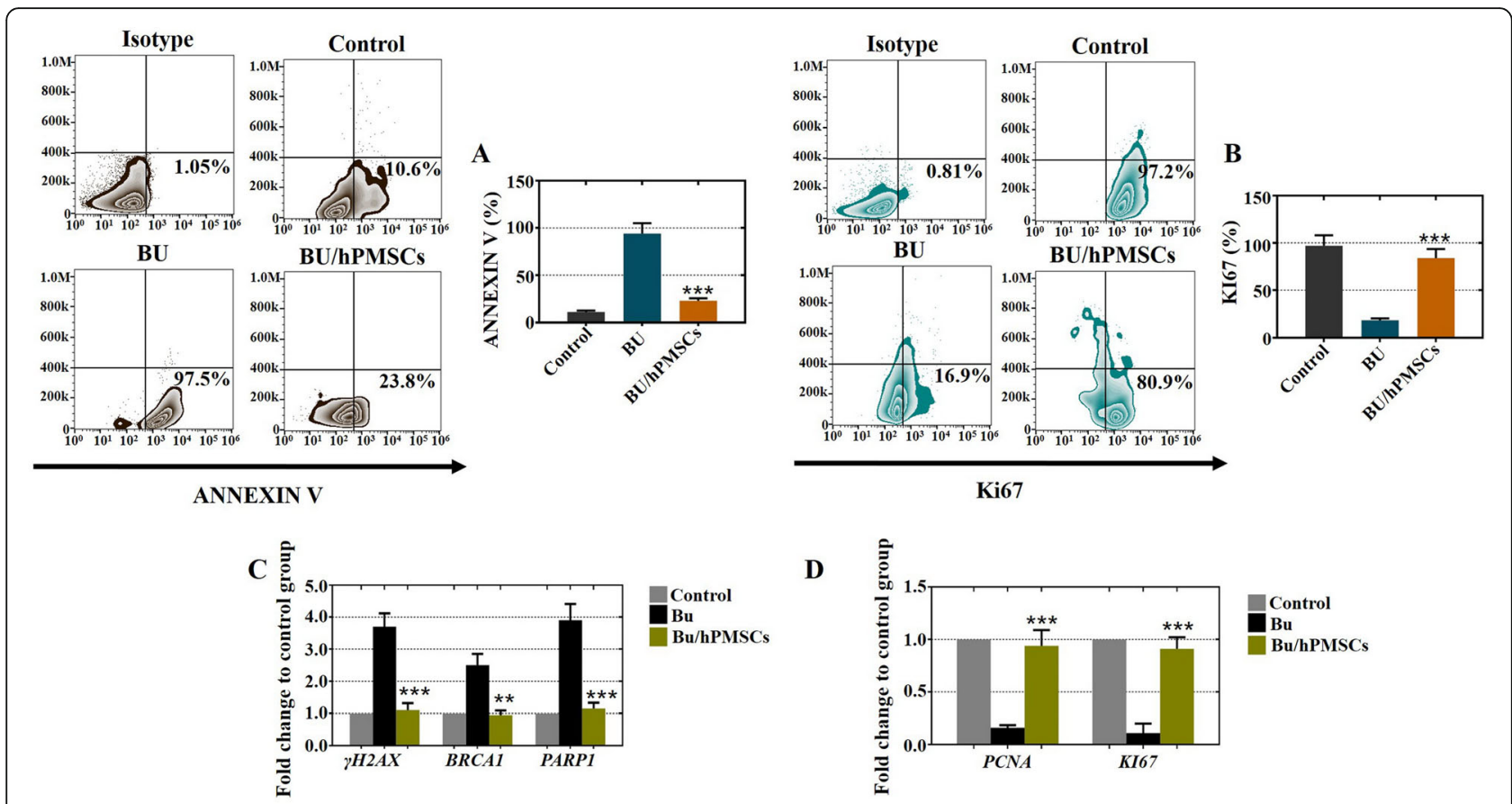

Fig. 3 In cultured Sertoli cells treated with busulfan, hPMSCs inhibited cell apoptosis and enhanced cell proliferation. a The FACS results indicated that hPMSC treatment inhibited the rate of apoptosis (Annexin V) in Sertoli cells. b The FACS results showed that hPMSC treatment improved the proliferation rate (Ki67) of Sertoli cells. c, $\mathbf{d}$ The qRT-PCR results showed that hPMSC treatment suppressed the expression of apoptotic genes ( $\gamma$ H2AX, BRCA1, and PARP1) and increased the expression of proliferative genes (PCNA and Ki67). All experiments were carried out three times, and the error bars indicate the SD. ${ }^{* *} p<0.01,{ }^{* * *} p<0.001$

busulfan-induced testicular toxicity was introduced to assess cell apoptosis and proliferation features after hPMSC injection. As expected, hPMSC treatment successfully increased the relative fluorescence intensities of BrdU and SCP3 in the BU/hPMSC group compared with the $\mathrm{BU}$ group (Fig. $4 \mathrm{a}-\mathrm{C}$ ). In agreement with the fluorescence microscopy results, we observed a rising trend in the mRNA levels of PCNA and Ki67 in the BU/hPMSC group compared with the BU group (Fig. 4e). Moreover, the mRNA levels of apoptotic genes such as $\gamma$-H2AX, BRCA1, and PARP1 revealed a decreasing trend in the BU/hPMSC group compared with the BU group (Fig. 4d).

\section{hPMSCs increased oxidative protection and decreased} oxidative damage in a mouse model of busulfan-induced testicular toxicity

We next sought to verify whether hPMSCs protect against oxidative stress and decrease oxidative damage in the busulfan-induced testis toxicity mouse model. The results of fluorescence microscopy, FACS, and ELISA indicated that hPMSCs rescued spermatogenic function by suppressing oxidative stress. As observed by fluorescence microscopy, hPMSCs successfully enhanced the relative fluorescence intensities of SIRT1 and PLZF in the BU/hPMSC group compared with the BU group (Fig. 5a-c). FACS analysis showed that after hPMSC treatment, the proportion of $\mathrm{ROS}^{+}$Sertoli cells was significantly lower in the BU/hPMSC group (30.3\%) than in the BU group (89.8\%) (Fig. 5d). Finally, the levels of antioxidant enzymes such as SOD and CAT recovered and maintained an increasing trend in the $\mathrm{BU} /$ hPMSC group, while MDA and LDH showed a declining trend.

\section{hPMSCs promoted autophagy in a mouse model of busulfan-induced testicular toxicity}

To further confirm the relationship between autophagy and spermatogenesis, fluorescence microscopy was used to investigate the colocalization of autophagy-associated proteins, including p62 and LC3. The results showed that the immunofluorescence signals of the autophagy markers p62 and LC3 increased in the BU group (Fig. 6a, b), indicating that autophagy was inhibited under busulfan induction. However, LC3 fluorescence vanished at 4 weeks after hPMSC treatment (Fig. 6a, b). A hallmark of autophagy, LC3 acts as a scaffold to recognize p62 and regulate protein turnover in autophagy. Moreover, the fluorescence of p62, a specific substrate of autophagy and an LC3-binding protein, disappeared at 4 weeks after hPMSC treatment. Additionally, in agreement with the immunofluorescence results, the mRNA levels of p62 

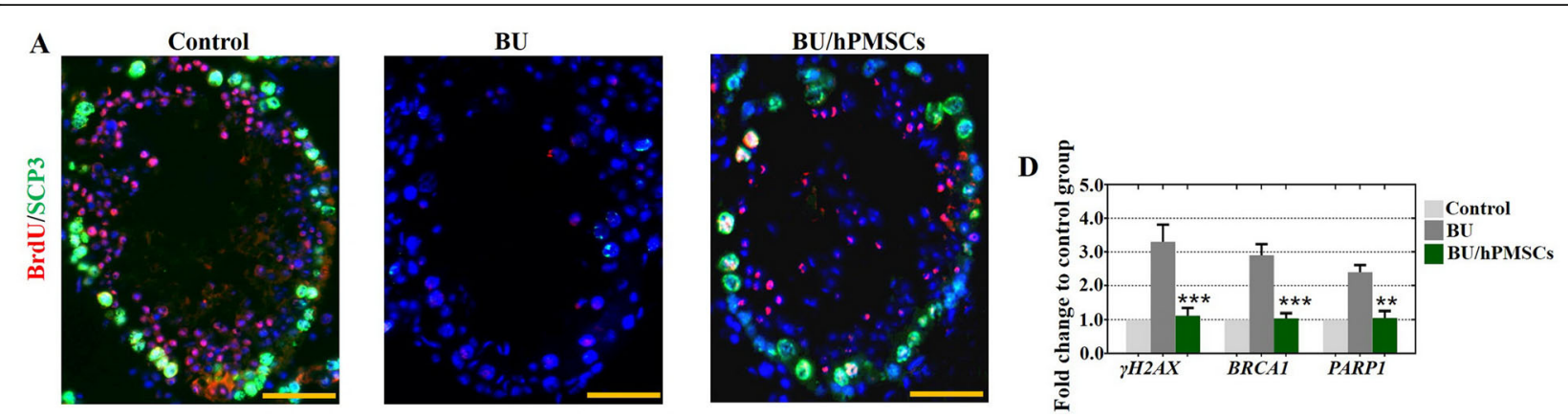

B

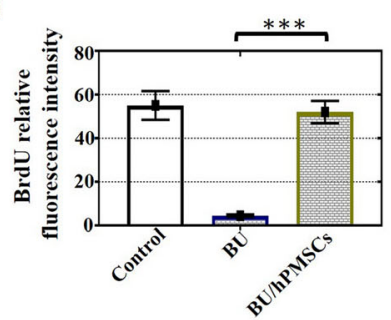

C

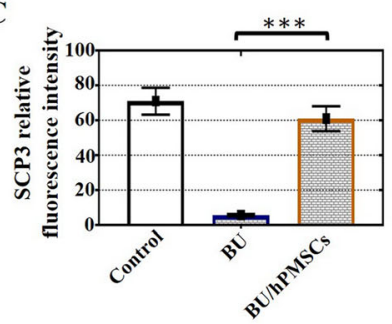

$\mathbf{E}$

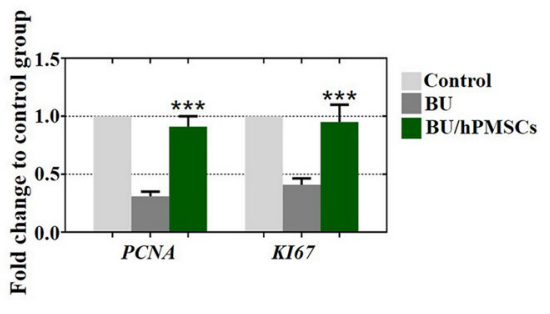

Fig. 4 hPMSCs improved cell proliferation and alleviated apoptosis of testes in the busulfan-induced testis toxicity mouse model. a-c The fluorescence intensities of BrdU (red) and SCP3 (green) in the three groups were detected by fluorescence microscopy. $\mathbf{d}$, e The mRNA expression of $\mathrm{Y}-\mathrm{H} 2 \mathrm{AX}, \mathrm{BRCA1}$, PARP1, PCNA, and Ki67 was determined by qRT-PCR. The error bars indicate the SD. ${ }^{* *} p<0.01,{ }^{* * *} p<0.001$

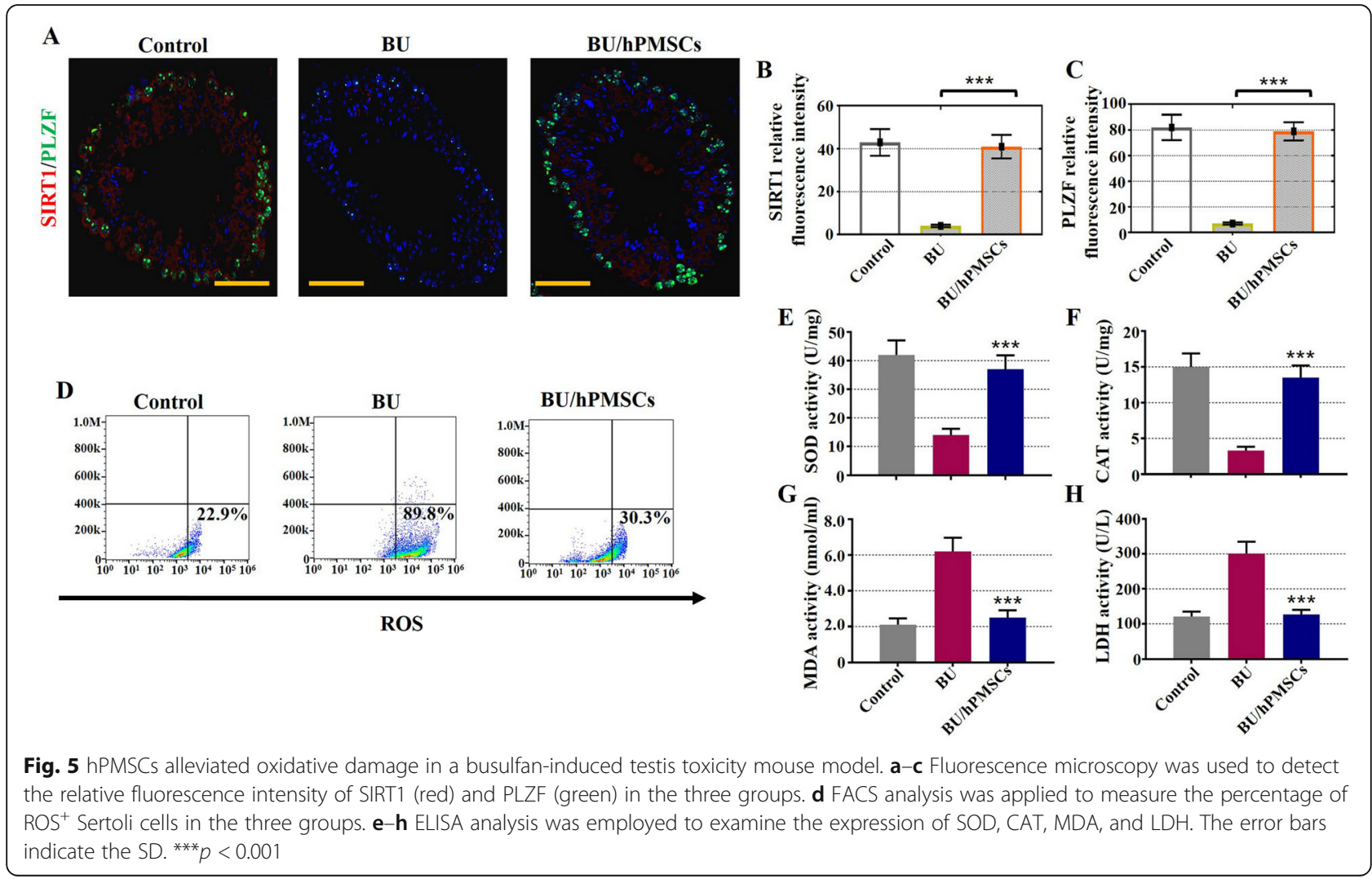




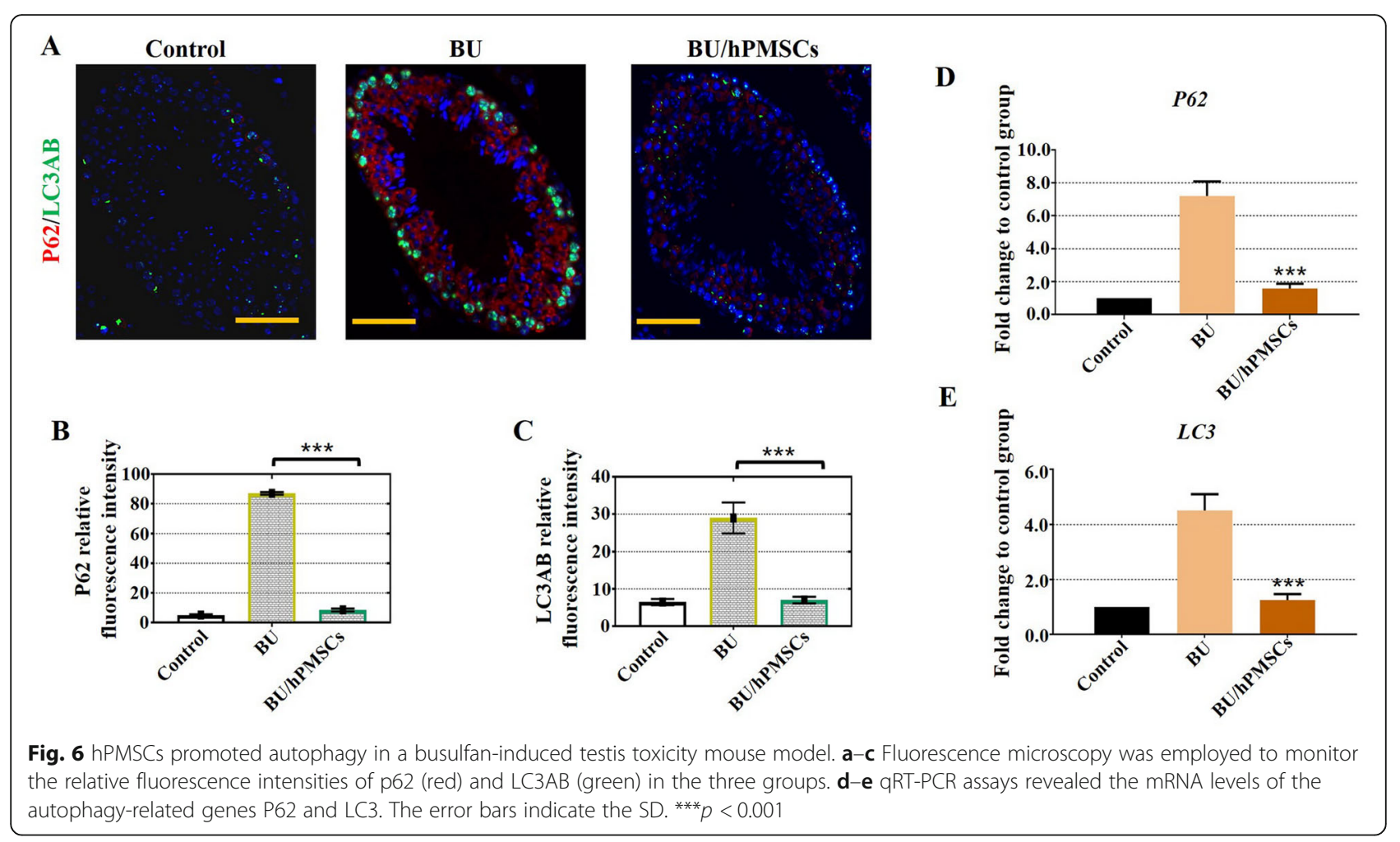

and LC3 showed trends similar to those of their protein levels (Fig. 6d-e).

\section{Discussion}

Chemotherapy with busulfan is an effective treatment for leukemia, especially in children. Nevertheless, the male reproductive system could be damaged by busulfan and develop oligospermia or azoospermia and finally permanent male sterility [24, 25]. In addition, previous studies have reported that male sterility in mice induced by busulfan is similar to that in humans $[8,26]$. In the current research, we found that hPMSC treatment restored spermatogenesis in a mouse model of busulfaninduced testicular toxicity and boosted the proliferation of busulfan-induced mouse Sertoli cells by reducing apoptosis/oxidative stress and promoting autophagy. Consequently, we sought to determine the underlying mechanisms by which hPMSCs improve spermatogenesis by using different analyses.

The previous studies have shown that transplantation of testicular endothelial cells alone could restore spermatogenesis in mice after chemotherapy-induced depletion of spermatogonial stem cells (SSC) [27], autologous spermatogonial stem cell (SSC) transplantation could rescue some forms of male infertility caused by Cldn 11 deficiency [28] or alginate oligosaccharides improved testis and blood metabolomes to support the recovery of spermatogenesis [29]. Our research also confirmed that hPMSCs are ideal for restoring spermatogenesis in the testes of mice induced by busulfan [22]. However, the interaction between transplantation of hPMSCs and testis toxicity induced by busulfan has not been explored. By using histological analysis, we confirmed that the number of seminiferous tubules with fluid-filled cavities decreased obviously after hPMSC transplantation (Fig. 1). Additionally, the testosterone level of the hPMSC-treated group returned to normal at 4 weeks after hPMSC treatment, which agreed with the results of our preceding study [22] (Fig. 1). The weight, size, and semen parameters of the testis recovered to normal values after hPMSC injection (Fig. 2). In accordance with our outcomes, busulfan-induced testes of mice transplanted with TECs were similar in size to those of control-injected mice [27]. Our results revealed that the overall number of sperm cells as well as the ratio of sperm cells with normal morphology to those with abnormal morphology were obviously elevated after hPMSC injection (Fig. 2).

Busulfan treatment was shown to lead to ROSmediated apoptosis [30]; apoptosis is a crucial process in testis development because it manages the proportion of germ cells and Sertoli cells to maintain efficient spermatogenesis [31]. Our study showed that hPMSCs have the ability to suppress the apoptosis of Sertoli cells and enhance their rate of proliferation in vivo and in vitro (Figs. 3 and 4). Moreover, our previous research also confirmed this conclusion since it demonstrated that hPMSCs alleviated cell apoptosis and enhanced cell 
proliferation to improve premature ovarian insufficiency [12]. ROS are inhibited in stem cell self-renewal and believed to be destructive for spermatogenesis [7]. Our results demonstrated that treatment with hPMSCs suppressed the levels of ROS (Fig. 5). Similar to our findings, hPMSCs were shown to protect against oxidative damage in $\mathrm{CD} 4^{+} \mathrm{T}$ cells by activating Akt-regulated Nrf2 antioxidant signaling [32].

Early studies discovered that the lysosomes of the seminiferous epithelium displayed a cyclical pattern and that autophagy was active in Sertoli cells [33, 34]. In the current study, we found that the autophagy markers p62 and LC3 aggregated in Sertoli cells and mouse testes after busulfan induction not only at the protein level but also at the mRNA level (Fig. 6). As two primary markers of autophagy, p62 and LC3 accumulate when autophagy is inhibited and are reduced when autophagy is induced [35]. Additionally, autophagy is inhibited by mTOR after busulfan treatment in mouse spermatogonial progenitor cells [36]. Collectively, the results from these studies showed that autophagy protected spermatogenesis and Sertoli cells from busulfaninduced stress, which may provide evidence for an important role for hPMSCs in the clinic.

\section{Conclusions}

In this study, we investigated the ability of hPMSCs to protect spermatogenic cells against busulfan-induced injury. By upregulating proliferation markers (Ki67, PCNA, BrdU, and SCP3), antioxidant markers (SIRT1, PLZF, SOD, and CAT), and autophagy markers (p62 and $\mathrm{LC} 3 \mathrm{AB}$ ) and downregulating apoptosis markers (Annexin $\mathrm{V}, \gamma$-H2AX, BRCA1, and PARP1) and oxidative markers (MDA and LDH), hPMSCs have substantial potential for repairing busulfan-disrupted spermatogenesis through repressing oxidative stress and apoptosis and enhancing cell proliferation and autophagy. Therefore, these results implied that hPMSCs played a vital role in enhancing cell proliferation and autophagy as well as inhibiting apoptosis and oxidative stress to restore male fertility impaired by busulfan.

\begin{abstract}
Abbreviations
hPMSCs: Human placental mesenchymal stem cells; ROS: Reactive oxygen species; MSCs: Mesenchymal stem cells; SSC: Spermatogonial stem cell; SPCs: Spermatogonial progenitor cells; ELISA: Enzyme-linked immunosorbent assay; FACS: Fluorescence-activated cell sorting; RT-PCR: reverse transcriptionpolymerase chain reaction; qPCR: Quantitative polymerase chain reaction; HE: Hematoxylin and eosin; MDA: Malondialdehyde; SOD: Superoxide dismutase; CAT: Catalase; LDH: Lactate dehydrogenase
\end{abstract}

\section{Supplementary Information}

The online version contains supplementary material available at https://doi. org/10.1186/s13287-021-02275-z.

Additional file 1: Supplemental Table 1. Designations, sequences, and the sizes of real-time PCR amplicons.

\section{Authors' contributions}

J.L. and Z.L. performed qPCR, HE staining, ELISA, and immunofluorescence experiments in vivo and in vitro. M.S. and J.L. took part in the statistical analysis and drawing figures. Western blot and FACS assays were carried out by J.L., L.T., and L.Z. W.X., L.T., and L. Z participated in the mice feeding. B.H. and H.L. designed all experiments and composed the manuscript. The authors read and approved the final manuscript.

\section{Funding}

This study is supported by the National Natural Science Foundation of China (81801515, 81801478), Suzhou talent training program (GSWS2019005), Suzhou introduce expert team of clinical medicine (SZYJTD201708), and Open project of State Key Laboratory of Reproductive Medicine (SKLRMK202008).

\section{Availability of data and materials}

All the data generated or analyzed during this study are included in this published rticle.

\section{Declarations}

Ethics approval and consent to participate

The use of human placental mesenchymal stem cells was in accordance with the relevant guidelines, and regulations and the experimental protocols were approved by the Medical Ethics Committee of the Suzhou Hospital Affiliated to Nanjing Medical University.

Our investigation using experimental animals and ethical approval were conducted on the basis of the Nanjing Medical University Animal Center's specific guidelines and standards.

We obtained informed consents from the donors.

\section{Consent for publication}

Not applicable

\section{Competing interests}

The authors declare no conflicts of interest.

\section{Author details}

${ }^{1}$ Center of Reproduction and Genetics, The affiliated Suzhou Hospital of Nanjing Medical University, Suzhou Municipal Hospital, Gusu School, State Key Laboratory of Reproductive Medicine, Nanjing Medical University, Suzhou 215002, China. ${ }^{2}$ Medical College of Soochow University, 199 Renai Road, Industrial Park District, Suzhou 215123, China.

Received: 23 December 2020 Accepted: 9 March 2021

Published online: 20 March 2021

\section{References}

1. Nishimura H, L'Hernault SW. Spermatogenesis. Curr Biol. 2017;27(18):R98894. https://doi.org/10.1016/j.cub.2017.07.067.

2. Hai Y, Hou J, Liu Y, Liu Y, Yang H, Li Z, He Z. The roles and regulation of Sertoli cells in fate determinations of spermatogonial stem cells and spermatogenesis. Semin Cell Dev Biol. 2014;29:66-75. https://doi.org/10.101 6/j.semcdb.2014.04.007.

3. Matzuk MM, Lamb DJ. The biology of infertility: research advances and clinical challenges. Nat Med. 2008;14(11):1197-213. https://doi.org/10.1038/ nm.f.1895.

4. Zhou Q, Wang M, Yuan $Y$, Wang $X$, Fu R, Wan H, Xie M, Liu M, Guo X, Zheng Y, Feng G, Shi Q, Zhao XY, Sha J, Zhou Q. Complete meiosis from embryonic stem cell-derived germ cells in vitro. Cell Stem Cell. 2016;18(3): 330-40. https://doi.org/10.1016/j.stem.2016.01.017.

5. Levine $H$, Jørgensen $N$, Martino-Andrade A, Mendiola J, Weksler-Derri D, Mindlis I, Pinotti R, Swan SH. Temporal trends in sperm count: a systematic review and meta-regression analysis. Hum Reprod Update. 2017;23(6):64659. https://doi.org/10.1093/humupd/dmx022.

6. Liu FJ, Dong WY, Zhao H, Shi XH, Zhang YL. Effect of molybdenum on reproductive function of male mice treated with busulfan. Theriogenology. 2019;126:49-54. https://doi.org/10.1016/j.theriogenology.2018.12.002.

7. Morimoto H, Iwata K, Ogonuki N, Inoue K, Atsuo O, Kanatsu-Shinohara M, Morimoto T, Yabe-Nishimura C, Shinohara T. ROS are required for mouse 
spermatogonial stem cell self-renewal. Cell Stem Cell. 2013;12(6):774-86. https://doi.org/10.1016/j.stem.2013.04.001.

8. Panahi M, et al. Busulfan induced azoospermia: stereological evaluation of testes in rat. Vet Res Forum. 2015;6(4):273-8.

9. Zhang X, Xia Q, Wei R, Song H, Mi J, Lin Z, Yang Y, Sun Z, Zou K. Melatonin protects spermatogonia from the stress of chemotherapy and oxidation via eliminating reactive oxidative species. Free Radic Biol Med. 2019;137:74-86. https://doi.org/10.1016/j.freeradbiomed.2019.04.009.

10. Xu LL, Liu ML, Wang JL, Yu M, Chen JX. Saligenin cyclic-o-tolyl phosphate (SCOTP) induces autophagy of rat spermatogonial stem cells. Reprod Toxicol. 2016;60:62-8. https://doi.org/10.1016/j.reprotox.2016.01.004.

11. Trounson A, McDonald C. Stem cell therapies in clinical trials: progress and challenges. Cell Stem Cell. 2015;17(1):11-22. https://doi.org/10.1016/j.stem.2 015.06.007.

12. Ding C, Zou Q, Wu Y, Lu J, Qian C, Li H, Huang B. EGF released from human placental mesenchymal stem cells improves premature ovarian insufficiency via NRF2/HO-1 activation. Aging (Albany NY). 2020;12(3):2992-3009. https:// doi.org/10.18632/aging.102794.

13. Mizushima N, Komatsu M. Autophagy: renovation of cells and tissues. Cell. 2011;147(4):728-41. https://doi.org/10.1016/j.cell.2011.10.026.

14. Mizushima N, Yoshimori T, Ohsumi Y. The role of Atg proteins in autophagosome formation. Annu Rev Cell Dev Biol. 2011;27(1):107-32. https://doi.org/10.1146/annurev-cellbio-092910-154005.

15. Yang Z, Klionsky DJ. An overview of the molecular mechanism of autophagy. Curr Top Microbiol Immunol. 2009;335:1-32. https://doi.org/10.1 007/978-3-642-00302-8_1.

16. Tsukamoto S, Kuma A, Murakami M, Kishi C, Yamamoto A, Mizushima N. Autophagy is essential for preimplantation development of mouse embryos. Science. 2008;321(5885):117-20. https://doi.org/10.1126/science.11 54822.

17. Liu C, Wang H, Shang Y, Liu W, Song Z, Zhao H, Wang L, Jia P, Gao F, Xu Z, Yang L, Gao F, Li W. Autophagy is required for ectoplasmic specialization assembly in sertoli cells. Autophagy. 2016;12(5):814-32. https://doi.org/10.1 080/15548627.2016.1159377.

18. Shang $Y$, Wang H, Jia P, Zhao H, Liu C, Liu W, Song Z, Xu Z, Yang L, Wang Y, Li W. Autophagy regulates spermatid differentiation via degradation of PDLI M1. Autophagy. 2016;12(9):1575-92. https://doi.org/10.1080/15548627.201 6.1192750.

19. Rehman R, Amjad S, Tariq H, Zahid N, Akhter M, Ashraf M. Oxidative stress and male infertility: a cross sectional study. J Pak Med Assoc. 2020;70(3): 461-6. https://doi.org/10.5455/JPMA.12992.

20. Forand A, Bernardino-Sgherri J. A critical role of PUMA in maintenance of genomic integrity of murine spermatogonial stem cell precursors after genotoxic stress. Cell Res. 2009;19(8):1018-30. https://doi.org/10.1038/cr.2 009.50 .

21. Li B, He X, Zhuang M, Niu B, Wu C, Mu H, Tang F, Cui Y, Liu W, Zhao B, Peng S, Li G, Hua J. Melatonin ameliorates busulfan-induced spermatogonial stem cell oxidative apoptosis in mouse testes. Antioxid Redox Signal. 2018; 28(5):385-400. https://doi.org/10.1089/ars.2016.6792.

22. Qian C, Meng Q, Lu J, Zhang L, Li H, Huang B. Human amnion mesenchymal stem cells restore spermatogenesis in mice with busulfaninduced testis toxicity by inhibiting apoptosis and oxidative stress. Stem Cell Res Ther. 2020;11(1):290. https://doi.org/10.1186/s13287-020-01803-7.

23. Ding C, Zou Q, Wang F, Wu H, Chen R, Lv J, Ling M, Sun J, Wang W, Li H, Huang B. Human amniotic mesenchymal stem cells improve ovarian function in natural aging through secreting hepatocyte growth factor and epidermal growth factor. Stem Cell Res Ther. 2018;9(1):55. https://doi.org/1 0.1186/s13287-018-0781-9.

24. Ganjalikhan Hakemi S, et al. The effects of olive leaf extract on the testis, sperm quality and testicular germ cell apoptosis in male rats exposed to busulfan. Int J Fertil Steril. 2019;13(1):57-65.

25. Pacey AA, Eiser $\mathrm{C}$. The importance of fertility preservation in cancer patients. Expert Rev Anticancer Ther. 2014;14(5):487-9. https://doi.org/10.1586/1473 7140.2014.883283.

26. Panahi S, Abdollahifar MA, Aliaghaei A, Nazarian H, Paktinat S, Abdi S, Farahani RM. Application of stereological methods for unbiased estimation of sperm morphology in the mice induced by busulfan. Anat Cell Biol. 2017; 50(4):301-5. https://doi.org/10.5115/acb.2017.50.4.301.

27. Bhang DH, Kim BJ, Kim BG, Schadler K, Baek KH, Kim YH, Hsiao W, Ding BS, Rafii S, Weiss MJ, Chou ST, Kolon TF, Ginsberg JP, Ryu BY, Ryeom S. Testicular endothelial cells are a critical population in the germline stem cell niche. Nat Commun. 2018;9(1):4379. https://doi.org/10.1038/s41467-01806881-z.

28. Kanatsu-Shinohara M, Ogonuki N, Matoba S, Ogura A, Shinohara T. Autologous transplantation of spermatogonial stem cells restores fertility in congenitally infertile mice. Proc Natl Acad Sci U S A. 2020;117(14):7837-44. https://doi.org/10.1073/pnas.1914963117.

29. Zhao Y, Zhang P, Ge W, Feng Y, Li L, Sun Z, Zhang H, Shen W. Alginate oligosaccharides improve germ cell development and testicular microenvironment to rescue busulfan disrupted spermatogenesis. Theranostics. 2020;10(7):3308-24. https://doi.org/10.7150/thno.43189.

30. Iskandar K, Rezlan M, Yadav SK, Foo CHJ, Sethi G, Qiang Y, Bellot GL, Pervaiz S. Synthetic lethality of a novel small molecule against mutant KRASexpressing cancer cells involves AKT-dependent ROS production. Antioxid Redox Signal. 2016;24(14):781-94. https://doi.org/10.1089/ars.2015.6362.

31. Rodriguez I, Ody C, Araki K, Garcia I, Vassalli P. An early and massive wave of germinal cell apoptosis is required for the development of functional spermatogenesis. EMBO J. 1997;16(9):2262-70. https://doi.org/10.1093/ emboj/16.9.2262.

32. Xiong $Y$, Wang $Y$, Zhang J, Zhao N, Zhang H, Zhang A, Zhao D, Yu Z, Yin $Y$, Song L, Xiong Y, Luan X. hPMSCs protects against D-galactose-induced oxidative damage of CD4(+) T cells through activating Akt-mediated Nrf2 antioxidant signaling. Stem Cell Res Ther. 2020;1 1(1):468. https://doi.org/1 0.1186/s13287-020-01993-0.

33. Yefimova MG, Messaddeq N, Harnois T, Meunier AC, Clarhaut J, Noblanc A, Weickert JL, Cantereau A, Philippe M, Bourmeyster N, Benzakour O. A chimerical phagocytosis model reveals the recruitment by Sertoli cells of autophagy for the degradation of ingested illegitimate substrates. Autophagy. 2013;9(5):653-66. https://doi.org/10.4161/auto.23839.

34. Chen Y, Zhou Y, Wang X, Qian W, Han X. Microcystin-LR induces autophagy and apoptosis in rat Sertoli cells in vitro. Toxicon. 2013;76:84-93. https://doi. org/10.1016/j.toxicon.2013.09.005

35. Borgeson $\mathrm{E}$, et al. Lipoxin A4 attenuates obesity-induced adipose inflammation and associated liver and kidney disease. Cell Metab. 2015; 22(1):125-37. https://doi.org/10.1016/j.cmet.2015.05.003.

36. Wei R, Zhang X, Cai Y, Liu H, Wang B, Zhao X, Zou K. Busulfan suppresses autophagy in mouse spermatogonial progenitor cells via mTOR of AKT and p53 signaling pathways. Stem Cell Rev Rep. 2020;16(6):1242-55. https://doi. org/10.1007/s12015-020-10027-4.

\section{Publisher's Note}

Springer Nature remains neutral with regard to jurisdictional claims in published maps and institutional affiliations.
Ready to submit your research? Choose BMC and benefit from:
- fast, convenient online submission
- thorough peer review by experienced researchers in your field
- rapid publication on acceptance
- support for research data, including large and complex data types
- gold Open Access which fosters wider collaboration and increased citations
- maximum visibility for your research: over $100 \mathrm{M}$ website views per year
At BMC, research is always in progress.
Learn more biomedcentral.com/submissions 